\title{
Dense core vesicle markers in CSF and cortical tissues of patients with Alzheimer's disease
}

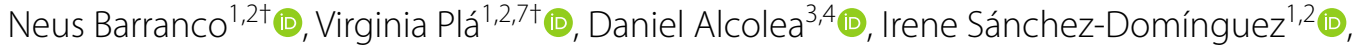 \\ Reiner Fischer-Colbrie ${ }^{5}$, Isidro Ferrer $2,4,6$ (D) Alberto Lleó ${ }^{3,4}$ (D) and Fernando Aguado ${ }^{1,2^{*}}$ (D)
}

\begin{abstract}
Background: New fluid biomarkers for Alzheimer's disease (AD) that reveal synaptic and neural network dysfunctions are needed for clinical practice and therapeutic trial design. Dense core vesicle (DCV) cargos are promising cerebrospinal fluid (CSF) indicators of synaptic failure in AD patients. However, their value as biomarkers has not yet been determined.
\end{abstract}

Methods: Immunoassays were performed to analyze the secretory proteins prohormone convertases $\mathrm{PC} 1 / 3$ and PC2, carboxypeptidase E (CPE), secretogranins SgIII and Sgll, and Cystatin C in the cerebral cortex $(n=45$, provided by Bellvitge University Hospital) and CSF samples ( $n=66$, provided by The Sant Pau Initiative on Neurodegeneration cohort) from AD patients ( $n=56)$ and age-matched controls $(n=55)$.

Results: In AD tissues, most DCV proteins were aberrantly accumulated in dystrophic neurites and activated astrocytes, whereas PC1/3, PC2 and CPE were also specifically accumulated in hippocampal granulovacuolar degeneration bodies. AD individuals displayed an overall decline of secretory proteins in the CSF. Interestingly, in AD patients, the CSF levels of prohormone convertases strongly correlated inversely with those of neurodegeneration markers and directly with cognitive impairment status.

Conclusions: These results demonstrate marked alterations of neuronal-specific prohormone convertases in CSF and cortical tissues of AD patients. The neuronal DCV cargos are biomarker candidates for synaptic dysfunction and neurodegeneration in $A D$.

Keywords: Alzheimer's disease, Biomarkers, Cerebral cortex, Cerebrospinal fluid, Granulovacuolar degeneration, PCSK1, PCSK2, Tau protein

\section{Background}

Alzheimer's disease (AD) is the most prevalent neurodegenerative disorder in the elderly [1]. Because currently there is no effective treatment or prevention for $\mathrm{AD}$, identification of $\mathrm{AD}$ fluid biomarkers in the

\footnotetext{
*Correspondence: faguado@ub.edu

${ }^{\dagger}$ Neus Barranco and Virginia Plá have contributed equally to this work

${ }^{1}$ Department of Cell Biology, Physiology and Immunology, Faculty of Biology, University of Barcelona, 08028 Barcelona, Spain

Full list of author information is available at the end of the article
}

neuropathological progression of the illness is crucial to clinical practice and therapeutic trial design [2-4]. The main clinical symptoms of AD are gradual and progressive memory and cognitive impairments, which strongly correlate with the cortical atrophy-related synaptic and neuronal loss in all affected brain regions [5-7]. Pathologically, AD is characterized by deposits of amyloid- $\beta(A \beta)$ peptides in extracellular senile plaques and accumulation of hyperphosphorylated tau protein in somatic neurofibrillary tangles and plaque-surrounding original author(s) and the source, provide a link to the Creative Commons licence, and indicate if changes were made. The images or other third party material in this article are included in the article's Creative Commons licence, unless indicated otherwise in a credit line to the material. If material is not included in the article's Creative Commons licence and your intended use is not permitted by statutory regulation or exceeds the permitted use, you will need to obtain permission directly from the copyright holder. To view a copy of this licence, visit http://creativecommons.org/licenses/by/4.0/. The Creative Commons Public Domain Dedication waiver (http://creativeco mmons.org/publicdomain/zero/1.0/) applies to the data made available in this article, unless otherwise stated in a credit line to the data. 
dystrophic neurites. In addition to the loss of neural circuitry and neuronal cell bodies, cerebral amyloid angiopathy, granulovacuolar degeneration (GVD), and Hirano bodies with glial activation have also been suggested as part of AD pathology [8].

Reliable cerebrospinal fluid (CSF) signatures have been developed for plaque and tangle pathologies and for associated neurodegenerative processes (reduced $A \beta_{1-42}$ and increased phosphorylated tau (P-tau) and total tau (T-tau) levels, respectively). These core CSF biomarkers are currently routinely used in clinical practice for diagnosis of $\mathrm{AD}$ in patients at the mild cognitive impairment or dementia stage of the disease [9]. Additionally, several reports have proposed certain microglial and astrocytic proteins, such as TREM2 and YKL-40, as biomarkers of glial activation in AD [10-13]. Importantly, as decreased synapses are a major quantitative correlate of loss of memory and cognition in AD brains [7], much attention is being focused on biomarkers to detect the degree of synaptic dysfunction and degeneration in early stages of AD. Novel CSF biomarker candidates for synaptic pathology include axonal and pre- and postsynaptic proteins, such as SNAP-25, Syntaxin 1B, neurogranin and neurofilament light chain [14-17].

Other potential CSF biomarkers for synaptic alterations in $\mathrm{AD}$ consist of released cargos of the so-called dense core vesicles (DCVs). As synaptic vesicles (SVs), DCVs belong to the regulated secretory pathway in neurons and also, presumably, in astrocytes $[18,19]$. In response to membrane depolarization, DCVs release a variety of neuropeptides and growth factors (e.g. brain-derived neurotrophic factor [BDNF]) as well as distinctive molecular components, such as chromogranins $(\mathrm{Cg})$, secretogranins (Sg), and processing enzymes [18]. Although DCVs do not accumulate within synaptic compartments as do SVs, the vast majority of fusion events occur at synaptic boutons and axons [20,21]. Interestingly, a major and ubiquitous constituent of the DCV matrix, CgA, was one of the first biochemical biomarker candidates for $\mathrm{AD}$ synaptic degeneration $[22,23]$. Recent advances in proteomic technology have identified secreted DCV proteins in CSF screens for AD patients, such as the prototype granins $\mathrm{CgA}$ and $\mathrm{CgB}$ and the non-classical granin SgVII (usually called VGF, the nerve growth factor inducible protein VGF) [24, 25]. These observations suggest that DCV proteins may be promising biomarkers of synaptic loss in AD. However, changes in DCV cargos in AD CSF observed in different proteomic and immunological analyses offer variable results, or have not been completely validated [26, 27]. Here, we investigated changes in DCV proteins in the CSF and brain samples of AD patients. Specifically, we examined the neuronal prohormone convertases $\mathrm{PC} 1 / 3$ and $\mathrm{PC} 2$, and the neuronal and astroglial carboxypeptidase E (CPE), SgIII and SgII [28-33]. Additionally, we examined the secretory protein Cystatin $\mathrm{C}(\mathrm{CysC})$, a neuronal and astrocytic protease inhibitor involved in $\mathrm{AD}$, located mainly in lysosomes and possibly in DCVs $[34,35]$.

\section{Materials and methods Brain tissues}

Post-mortem human $\mathrm{AD}(n=23)$ and non-AD $(n=22)$ brain samples (aged 49-86) were obtained from the Institute of Neuropathology Brain Bank IDIBELL Hospital Universitari de Bellvitge (Hospitalet de Llobregat, Spain) under an agreement with the local ethics committee; demographic data are presented in Table 1. Individuals were selected based on the post-mortem diagnosis of $\mathrm{AD}$ according to the $\mathrm{ABC}$ score $(\mathrm{A}$, Amyloid phases Thal; B, Braak stages of neurofibrillary tangle pathology; C, CERAD stages) following the National Institute on Aging-Alzheimer's Association (NIA-AA) clinical research criteria [36]. The $\mathrm{AD}$-diagnosed subjects corresponded to A3-A4, V-VI (B3) and C3, whereas the non$\mathrm{AD}$ subjects were A0, 0-I/II (B0-BI) and C0.

Table 1 Demographic information for Alzheimer's disease and control brains

\begin{tabular}{|c|c|c|c|c|c|}
\hline & Age (years) & Gender & $\begin{array}{l}\text { Post-mortem time } \\
\text { (hours) }\end{array}$ & Cortical region & Type of investigation \\
\hline Control $(n=3)$ & $71.0( \pm 7.0)$ & $1 \mathrm{M} / 2 \mathrm{~F}$ & $5.2( \pm 2.8)$ & \multirow[t]{2}{*}{ Parietal cortex } & \multirow[t]{2}{*}{ Immuno-histochemistry } \\
\hline $\operatorname{AD}(n=5)$ & $78.4( \pm 4.6)$ & $5 F$ & $5.7( \pm 3.8)$ & & \\
\hline Control $(n=5)$ & $69.6( \pm 5.3)$ & $3 \mathrm{M} / 2 \mathrm{~F}$ & $9.3( \pm 4.0)$ & \multirow[t]{2}{*}{ Hippocampus } & \multirow{2}{*}{$\begin{array}{l}\text { Immuno-histochem- } \\
\text { istry }\end{array}$} \\
\hline $\operatorname{AD}(n=4)$ & $75.8( \pm 6.5)$ & $2 \mathrm{M} / 2 \mathrm{~F}$ & $5.9( \pm 2.2)$ & & \\
\hline Control $(n=7)$ & $73.7( \pm 7.3)$ & $4 \mathrm{M} / 3 \mathrm{~F}$ & $6.0( \pm 2.8)$ & \multirow[t]{2}{*}{ Parietal cortex } & \multirow[t]{2}{*}{ Western blot } \\
\hline $\operatorname{AD}(n=7)$ & $80.1( \pm 6.6)$ & $2 \mathrm{M} / 5 \mathrm{~F}$ & $6.3( \pm 3.4)$ & & \\
\hline Control $(n=7)$ & $73.3( \pm 13.1)$ & $7 \mathrm{M}$ & $6.6( \pm 4.7)$ & \multirow[t]{2}{*}{ Hippocampus } & \multirow[t]{2}{*}{ Western blot } \\
\hline $\mathrm{AD}(n=7)$ & $81.9( \pm 3.7)$ & $4 \mathrm{M} / 3 \mathrm{~F}$ & $6.4( \pm 1.9)$ & & \\
\hline
\end{tabular}

$F$, female; $M$, male 


\section{Lumbar CSF samples}

Both AD patients and control subjects (healthy volunteers) were recruited from the SPIN cohort in the Memory Unit at the Hospital de la Santa Creu i Sant Pau [37]. This study was approved by the local ethics committee and was carried out in accordance with the Declaration of Helsinki. All patients (or their nearest relatives) and controls gave informed consent to participate in the study. Extensive clinical, neuropsychological, MRI and molecular examinations were performed in all subjects. CSF samples $(n=66)$ were collected by lumbar puncture between 9 am and noon. Centrifugation at $4{ }^{\circ} \mathrm{C}$ for $10 \mathrm{~min}$ at $2000 \times \mathrm{g}$ and storage of $500 \mu \mathrm{l}$ aliquots in polypropylene tubes at $-80^{\circ} \mathrm{C}$ were accomplished within $1 \mathrm{~h}$ after collection. All AD patients fulfilled clinical criteria for probable AD according to the revised NIA-AA criteria [38] and had a CSF biomarker profile consisting of decreased $A \beta_{1-42}$ plus high T-tau and P-tau levels (ELISA tests from Innogenetics, Ghent, Belgium), indicating high likelihood of being due to AD. The cut-off values we used to define our AD cohort in this study were $550 \mathrm{pg} / \mathrm{ml}$ for $\mathrm{A} \beta_{1-42}, 350 \mathrm{pg} / \mathrm{ml}$ for T-tau, and $61 \mathrm{pg} / \mathrm{ml}$ for P-tau [39]. The control group was defined according to the following criteria: objective cognitive performance within the normal range (performance within 1.5 standard deviation) on all tests from a specific test battery, clinical dementia rating scale score of 0 , no significant psychiatric symptoms or previous neurological disease, and a non-pathological CSF biomarker profile. The average Mini-Mental State Examination (MMSE) score was $21.6 \pm 4.4$ for $\mathrm{AD}$ patients, whereas control subjects had a score of 28 or higher. $\mathrm{AD}$ and control groups were well matched for age at CSF collection. Demographic information is presented in Table 2.

\section{Antibodies}

Home-made and commercial antibodies against DCV proteins used in this study have been extensively validated for western blot and immunohistochemical methods in previous papers and recognize processed and precursor molecular forms. Polyclonal antibodies against PC2 (LS18 kindly provided by Dr I. Lindberg, University of Maryland) and SgII/Secretoneurin have been described elsewhere [40, 41]. Polyclonal antibodies against $\mathrm{PC} 1 / 3$ were purchased from Abcam (ab3532, Abcam Plc, Cambridge, UK) and Thermo (PA1-057, Thermo Fisher Scientific, Waltham, MA) and polyclonal antibodies against PC2 were from GeneTex (GTX23533, GeneTex Inc, Irvine, CA) [42-44]. Polyclonal antibodies against SgIII (HPA006880, Prestige Antibodies ${ }^{\circledR}$ supported by The Human Protein Atlas) $[29,45]$ and monoclonal anti- $\beta$ actin peroxidase antibodies (AC-15) were purchased from Sigma (Sigma-Aldrich, Diesenhofen, Germany). Monoclonal and polyclonal antibodies against CPE were obtained from BD Biosciences (610758, BD Transduction Laboratories, San Jose, CA) and GeneTex (GTX23533, GeneTex Inc), respectively $[45,46]$. Polyclonal antibodies against CysC (ABC20) [47] and monoclonal antibodies against GFAP (MAB3402) were obtained from Millipore Iberica (Madrid, Spain). Monoclonal and polyclonal antibodies against CHMP2B (MAB7509) and CK1 $\delta$ (AF4568) were purchased from R\&D Systems (Minneapolis, MN). Monoclonal antibodies against LAMP-1 (H4A3) and neurofilament light chain (2835) were obtained from Developmental Studies Hybridoma Bank at the University of Iowa (Iowa City, Iowa) and Cell Signaling (Leiden, The Netherlands), respectively. Antibodies against A $\beta$ (M087201-2) and hyperphosphorylated tau (AT8) were from DAKO (Glostrup, Denmark) and Innogenetics (Gent, Belgium), respectively. A complete antibody list is provided in Additional file 1: Table S1.

\section{Immunohistochemistry}

Human brain samples were fixed in $4 \%$ paraformaldehyde in $0.1 \mathrm{M}$ phosphate buffer, $\mathrm{pH}$ 7.4, by immersion. After being cryoprotected in a $30 \%$ sucrose solution, the samples were frozen and sectioned with a cryostat. For peroxidase immunohistochemistry, histological sections were blocked for $30 \mathrm{~min}$ in phosphate buffered saline (PBS) supplemented with 10\% methanol and 3\% $\mathrm{H}_{2} \mathrm{O}_{2}$ and then washed in PBS. Pretreatment with formic acid was used to enhance labeling of plaques. To avoid nonspecific binding, brain sections were blocked in PBS containing $10 \%$ serum, $0.2 \%$ glycine, $0.1 \%$ Triton $\mathrm{X}-100$, and $0.2 \%$ gelatin for $1 \mathrm{~h}$ at room temperature.

Table 2 Demographics and CSF profiles of individuals

\begin{tabular}{|c|c|c|c|c|c|c|c|c|}
\hline & Age (years) & Gender & MMSE & $\begin{array}{l}\text { APOE allelic } \\
\text { frequency }\end{array}$ & $\begin{array}{l}\text { CSF A } \beta 42(\mathrm{pg} / \\
\mathrm{ml})\end{array}$ & CSF tau (pg/ml) & $\begin{array}{l}\text { CSF p-tau (pg/ } \\
\mathrm{ml})\end{array}$ & $\begin{array}{l}\text { CSF glucose } \\
(\mathrm{mmol} / \mathrm{l})\end{array}$ \\
\hline Control $(n=33)$ & $63.75( \pm 7.18)$ & $13 \mathrm{M} / 20 \mathrm{~F}$ & $29.21( \pm 0.96)$ & $\begin{array}{l}\varepsilon 2=0.05 \\
\varepsilon 3=0.83 \\
\varepsilon 4=0.12\end{array}$ & $836.09( \pm 154.72)$ & $221.97( \pm 57.44)$ & $43.38( \pm 10.39)$ & $3.46( \pm 0.51)$ \\
\hline $\mathrm{AD}(n=33)$ & $66.94( \pm 6.13)$ & $12 \mathrm{M} / 21 \mathrm{~F}$ & $21.58( \pm 4.39)^{* * *}$ & $\begin{array}{l}\varepsilon 2=0.03 \\
\varepsilon 3=0.44 \\
\varepsilon 4=0.53\end{array}$ & $\begin{array}{l}353.27 \\
( \pm 101.20)^{* * *}\end{array}$ & $\begin{array}{l}905.32 \\
( \pm 457.94)^{* * *}\end{array}$ & $99.33( \pm 31.32)^{* * *}$ & $3.39( \pm 0.51)$ \\
\hline
\end{tabular}

Data are presented as mean \pm SEM

*** $P<0.001$, Mann-Whitney test. $F$, female; $M$, male 
Incubations with the primary antibodies were carried out overnight at $4{ }^{\circ} \mathrm{C}$ in PBS containing $1 \%$ fetal bovine serum, $0.1 \%$ Triton $\mathrm{X}-100$ and $0.2 \%$ gelatin. Bound antibodies were detected using the avidin-biotin-peroxidase system (Vectastain $A B C$ kit, Vector Laboratories Inc., Burlingame, CA). PBS containing $0.05 \%$ diaminobenzidine (DAB) and $0.01 \% \mathrm{H}_{2} \mathrm{O}_{2}$ was used to visualize the peroxidase complex. Sections were mounted, dehydrated, and coverslipped in Eukitt ${ }^{\circledR}$ (Sigma-Aldrich, Diesenhofen, Germany). Semiquantitative analysis of $\mathrm{CysC}$ immunoreactivity on DAB-stained slices was carried out on the outer and inner layers of the $\mathrm{AD}$ and control parietal cortices $(n=3$, each). Images at $20 \times$ magnification ( 2 per section, 2 sections per sample) were randomly taken using identical acquisition microscope parameters. The signal intensity of $0.1 \times 0.1 \mathrm{~mm}^{2}$ fields was measured using the Image ${ }^{\circledR}$ software (NIH, Bethesda, MD). Levels of $\mathrm{Cys} C$ were initially quantified as arbitrary density units and subsequently $\mathrm{AD}$ values were expressed as a percent change from control measurement. Double-labeling fluorescent immunohistochemistry was carried out by incubation with different fluorochrome-conjugated secondary antibodies (Alexa Fluor 488 and Alexa Fluor 568; Molecular Probes, Eugene, OR), and cell nuclei were stained with Hoechst (Sigma-Aldrich, Diesenhofen, Germany). Endogenous autofluorescence was avoided using Sudan Black B (Sigma-Aldrich, Diesenhofen, Germany). Sections were mounted in Mowiol (Merk Chemicals Ltd., Nottingham, UK) and visualized with a Leica TCS SPE scanning confocal microscope. Colocalization analyses of DCV proteins with GVD markers were performed by ImageJ software, using the threshold-corrected Mander's correlation coeficient, which ranges between 1 (highcolocalization) and 0 (low-colocalization). The specificity of the immunolabeling was checked omitting primary antibodies, using nonspecific IgG instead of them and using a previous incubation of the primary antibodies with an excess of antigen (Proteintech Group Inc., Deansgate, Manchester, UK). No immunostaining was observed in these conditions.

\section{Western blotting and radioimmunoassay}

Equal volumes of lumbar CSF samples were collected in vials and brain tissues were homogenized in ice-cold lysis buffer containing $50 \mathrm{mM}$ Tris- $\mathrm{HCl}, \mathrm{pH} 7.4,150 \mathrm{mM}$ $\mathrm{NaCl}, 5 \mathrm{mM} \mathrm{MgCl} 2,1 \mathrm{mM}$ EGTA, 1\% Triton X-100, and a protease inhibitor cocktail (Roche Diagnostics GmbH, Mannheim, Germany). The CSF samples and postnuclear brain lysates were mixed with $3 \times$ sample buffer $(188 \mathrm{mM}$ Tris- $\mathrm{HCl}, 30 \%$ glycerol, 3\% SDS, $0.01 \%$ Bromophenol Blue, and $15 \% \beta$-mercaptoethanol), electrophoresed in 10\%-12\% SDS-acrylamide gel (Bio-Rad Laboratories, Hercules, CA), and then transferred to polyvinylidene difluoride immobilization membranes (Whatman $^{\circledR}$ Schleicher \& Schuell, Keene, NH). Tissue results were normalized for total protein content (data obtained from Ponceau staining scans). Membranes were blocked in 5\% nonfat milk powder solution in Tris-buffered saline and Tween-20 (TBST; $140 \mathrm{mM} \mathrm{NaCl}, 10 \mathrm{mM}$ Tris/HCl, $\mathrm{pH}$ 7.4 and $0.1 \%$ Tween-20) for $1 \mathrm{~h}$ at room temperature and then incubated with primary antibodies in blocking solution overnight at $4{ }^{\circ} \mathrm{C}$. After numerous washes in blocking buffer, the membranes were incubated for $1 \mathrm{~h}$ with horseradish peroxidase-conjugated secondary antibodies (Bio-Rad Laboratories, Hercules, CA). Enhanced chemiluminescence reagents $\mathrm{ECL}^{\mathrm{TM}}$ (GE Healthcare, Buckinghamshire, UK) and X-ray films (AGFA) were used to visualize bound antibodies. Blot images were taken with a scanner and densitometric values were obtained using a Java-based image processing software (Image ${ }^{\circledR}$ software). The amount of total proteins in brain homogenates $(10-15 \mu \mathrm{g})$ and CSF volume $(2-5 \mu \mathrm{l})$ and exposure times of the films were empirically determined to obtain the adequate linear range for quantitative analysis. For protein forms with different electrophoretic mobilities, a single average exposure of the film is shown in the figures, whereas quantitative analysis of each form was performed at different and suitable amounts of total protein/ volume and exposure time of the films.

The SgII/secretoneurin radioimmunoassay was performed as described previously [41]. In brief, samples were denatured to avoid protein degradation and antiserum was added in the radioimmunoassay buffer and incubated for $24 \mathrm{~h}$ at $4{ }^{\circ} \mathrm{C}$. Then iodinated secretoneurin $(200 \mathrm{cpm} / \mu \mathrm{L})$ was added and samples were incubated for an additional $24 \mathrm{~h}$ at $4{ }^{\circ} \mathrm{C}$. The non-bound tracer was separated by dextran-coated charcoal absorption and pulled down by centrifugation. The iodinated tracer remaining in the supernatant fraction was quantified, with a detection limit of 1-2 fmol.

\section{Statistical analysis}

Quantitative data were statistically analyzed using GraphPad Prism $6.01^{\circledR}$ software (GraphPad Software, San Diego, CA) with $t$-test and Mann-Whitney test. All data are presented as the means \pm SEM. Significance was set at $P<0.05$. Correlations of the measured values were examined using the Bonferroni-corrected Spearman correlation coefficient. A significance cutoff of $P \leq 0.0019$ based on Bonferroni correction of multiple comparisons and $P \leq 0.05$ in non-corrected comparisons were applied. 


\section{Results}

DCV markers are neuropathologically accumulated in dystrophic neurites and GVD bodies in the AD cerebral cortex

To examine DCV changes in the cerebral cortex of AD patients, we performed Western blotting and immunostaining analyses in homogenates and histological sections from AD patients and age-matched controls. PC1/3, PC2, CPE, SgIII and SgII were abundantly found by immunoblotting in cortical samples (Additional file 1: Fig. S1). In addition to the unprocessed and mature forms, higher and lower electrophoretic mobility bands were detected with polyclonal antibodies against DCV proteins, likely corresponding to the described aggregated and cleaved species [30-32]. A robust detection for all of these proteins was noted in CSF samples, essentially their precursor and mature forms. Volumes as small as $1 \mu \mathrm{L}$ were enough to detect some of these proteins in the CSF (i.e. SgIII). As previously reported, only the monomeric form of the secretory protease inhibitor CysC was detected in the CSF $(\sim 14 \mathrm{kDa})$, whereas cortical tissues also displayed oligomeric/aggregated species $[48,49]$. When performing analyses of similar CSF volumes, levels of membrane and cytosolic proteins such as synaptophysin (Syp) and $\beta$-actin (Additional file 1: Fig. $\mathrm{S} 1$ ), as well as the potential AD biomarker neurofilament light chain (data not shown), were under the detection limit. Thus, besides the abundance in brain tissues, DCV proteins are broadly detected in the CSF, feasibly corresponding with released species.

Next, we examined the levels of distinct molecular forms of secretory proteins in AD brains by immunoblotting ( $n=7$ per tissue and condition) (Fig. 1 and Additional file 1: Fig. S2). Comparing DCV protein amounts (normalized to membrane-transferred total protein) in hippocampus and parietal cortex of AD cases with controls, we only found changes for the $72-\mathrm{kDa}$ precursor form of PC2 (proPC2). The proPC2 species was increased 1.7-fold in parietal cortex $(P=0.038)$ and 2.4-fold in hippocampus $(P=0.0006)$. Interestingly, the $\sim 28 \mathrm{kDa}$ form of $\mathrm{CysC}$ was significantly decreased in the parietal cortex of $\mathrm{AD}$ patients $(35 \%, P=0.038)$. This electrophoretic band probably corresponds to dimeric or aggregated forms of $\mathrm{CysC}$, which have been associated with amyloid damage $[48,49]$. Finally, a prominent reduction was evident in the content of the SV-specific integral protein Syp both in parietal cortex $(30 \%, P=0.042)$ and in hippocampus $(50 \%, P=0.017)$ of $\mathrm{AD}$ patients. These results

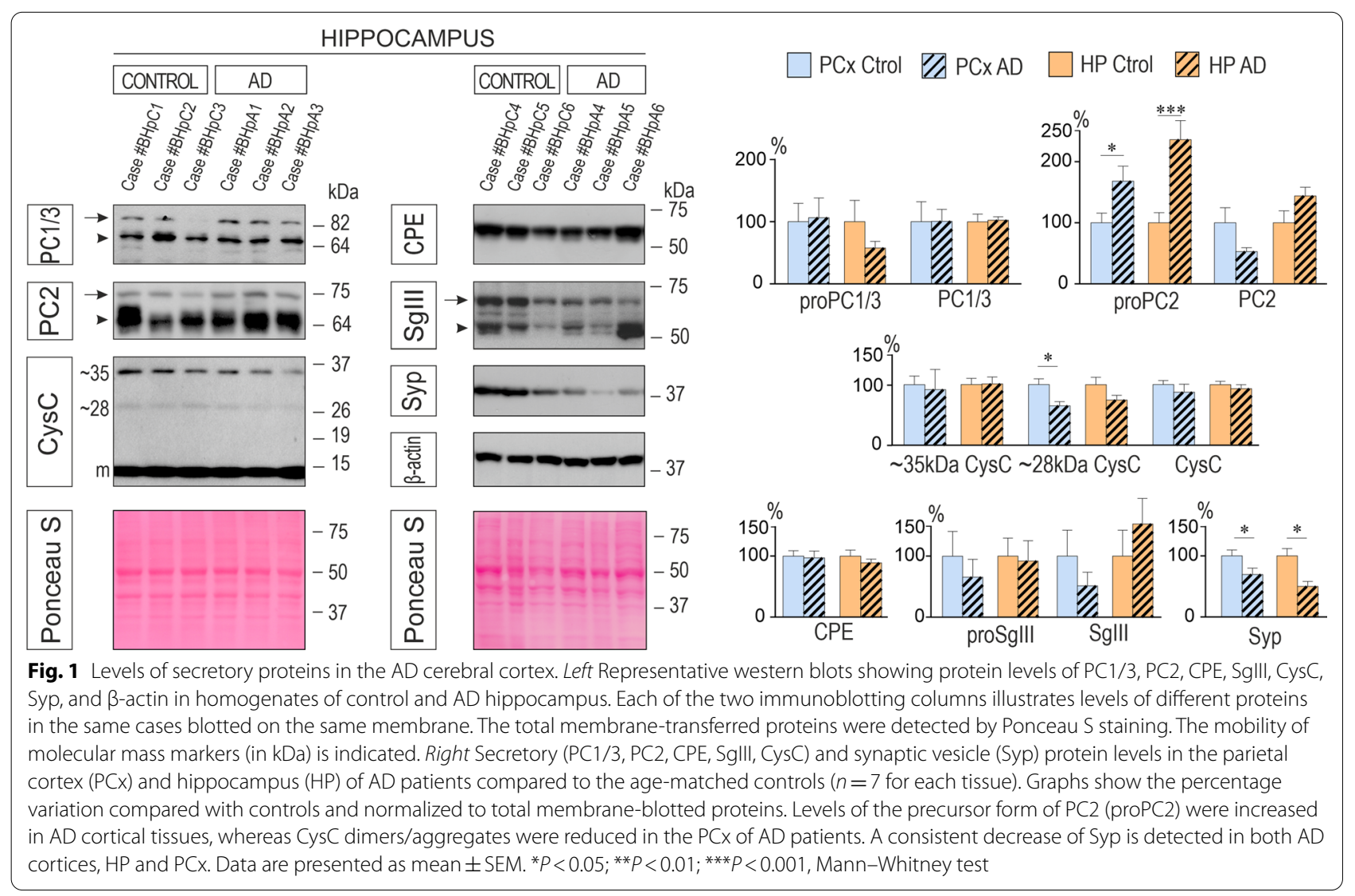


show that the global levels of different DCV markers are mostly preserved in $\mathrm{AD}$ cortices, whereas ubiquitous $\mathrm{SV}$ proteins are dramatically reduced.

To examine the alterations of DCV proteins in situ, we performed peroxidase immunohistochemical and confocal immunofluorescence analyses in brain sections from control $(n=8)$ and $\mathrm{AD}$ cases $(n=9)$. In controls, PC1/3, PC2, CPE, SgIII, SgII and CysC were widely distributed throughout the cerebral cortex, consistent with previous studies [45, 50-52] (Fig. 2). All of these proteins were abundant in neuronal populations of the neocortex and hippocampus (Fig. 2a), although a differential and robust immunolabeling for CPE was detected filling dendritic shafts (Fig. 2a, c). Immunostaining for SgIII, $\mathrm{CPE}$, and $\mathrm{Cys} C$ was also detected in $\mathrm{GFAP}^{+}$astrocytes (Fig. 2b), whereas prohormone convertases were absent in glial cells. In neurons, subcellular structures labeled for secretory proteins included somatic and dendritic granules, varicose fibers, and terminal-like buttons, as we previously reported [45]. Granular compartments immunostained for typical DCV markers were negative for the lysosomal marker LAMP1 (not shown), whereas CysC immunofluorescence was largely associated with $\mathrm{LAMP}^{+}{ }^{+}$structures (Fig. 2c). Immunostaining alterations for secretory proteins in $\mathrm{AD}$ cortices were mainly associated with senile plaques (Fig. 3a). All typical DCV components were aberrantly accumulated, to different degrees, in $\mathrm{AT}^{+}$dystrophic neurites surrounding amyloid plaques, in the parietal cortex and hippocampus (in each examined $\mathrm{AD}$ cases) (representative examples are shown in Fig. 3b, c). In some samples, intense immunolabeling for SgIII and CysC was detected in reactive astrocytes close to the amyloid deposits (data not shown), as described elsewhere [45, 51]. No major changes were detected for secretory proteins in non-plaque areas of the $\mathrm{AD}$ brains, including tangle-bearing neuronal somata identified by the AT8 antigen (excepting cells showing GVD, see below). Only a slight, but consistent, increase in $\mathrm{Cys} C$ was found in pyramidal neurons located in outer and inner layers of the $\mathrm{AD}$ parietal cortex (Additional file 1: Fig. S3).

Unexpectedly, we found GVD-shaped structures immunolabelled for some DCV proteins in CA1 pyramidal somata (and to a lesser extent in CA2 and subiculum) in each of the four examined AD hippocampi (Fig. 4a). These granules had strong immunostaining for $\mathrm{PC} 2$ and moderate immunostaining for $\mathrm{PC} 1 / 3$, whereas only one $\mathrm{AD}$ case displayed scarce $\mathrm{CPE}^{+}$large granules (Fig. 4a). An average of $241 \pm 4$ CA1 pyramidal neurons containing aberrant $\mathrm{PC}^{+}$granules per $\mathrm{mm}^{2}$ was observed in $\mathrm{AD}(n=4)$, whereas age-matched controls were virtually devoid of these (a few cells, and in only 1 out of 5 cases). Double labeling of $\mathrm{PC} 1 / 3, \mathrm{PC} 2$ or $\mathrm{CPE}$ and the established GVD markers CK1 $\delta$ and CHMP2B
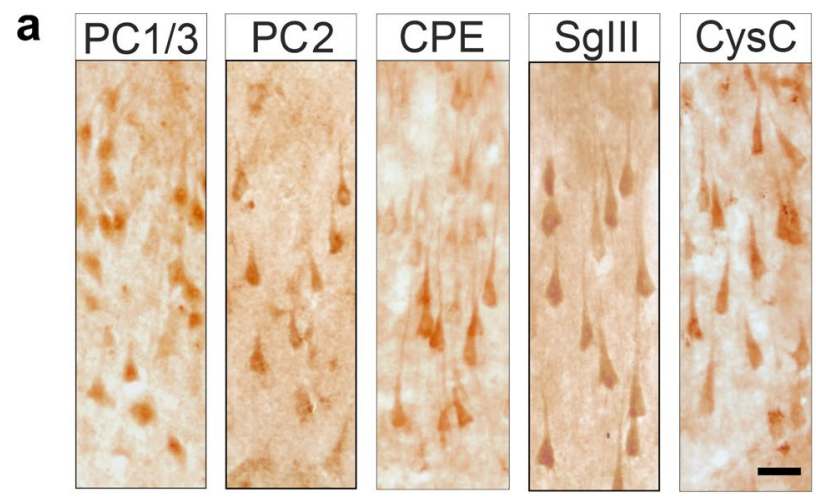

C
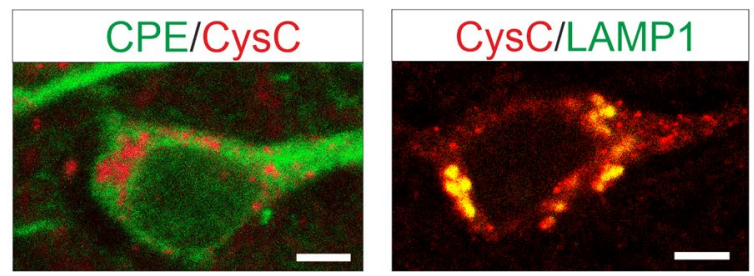

Fig. 2 Distribution of secretory proteins in the control cerebral cortex. a Peroxidase immunohistochemis secretory proteins (PC1/3, PC2, CPE, SgIII and CysC) in the CA1 region of the hippocampus. Scale bar, $20 \mu m$. b Peroxidase immunohistochemistry and double confocal immunofluorescences illustrating Sglll (grey matter), CPE and CysC (white matter) in neocortical astrocytes. Arrowheads indicate glial soma and projections. Scale bars, $10 \mu \mathrm{m}$. c Double immunofluorescences of two different neocortical pyramidal neurons showing CysC colocalization with the lysosomal marker LAMP1, but not with the DCV cargo CPE. Scale bars, $5 \mu \mathrm{m}$ 
a
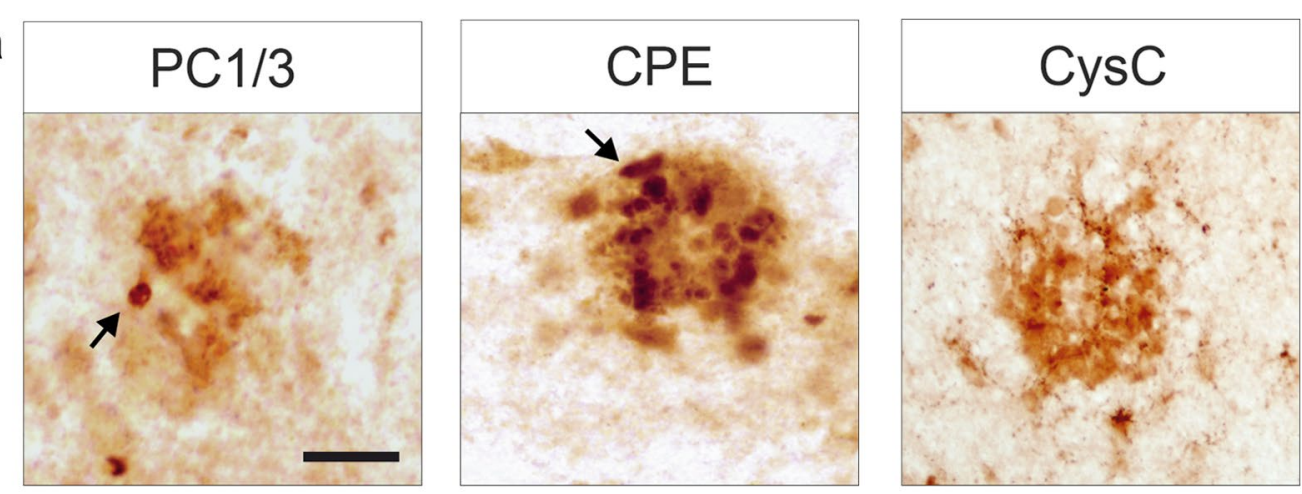

b
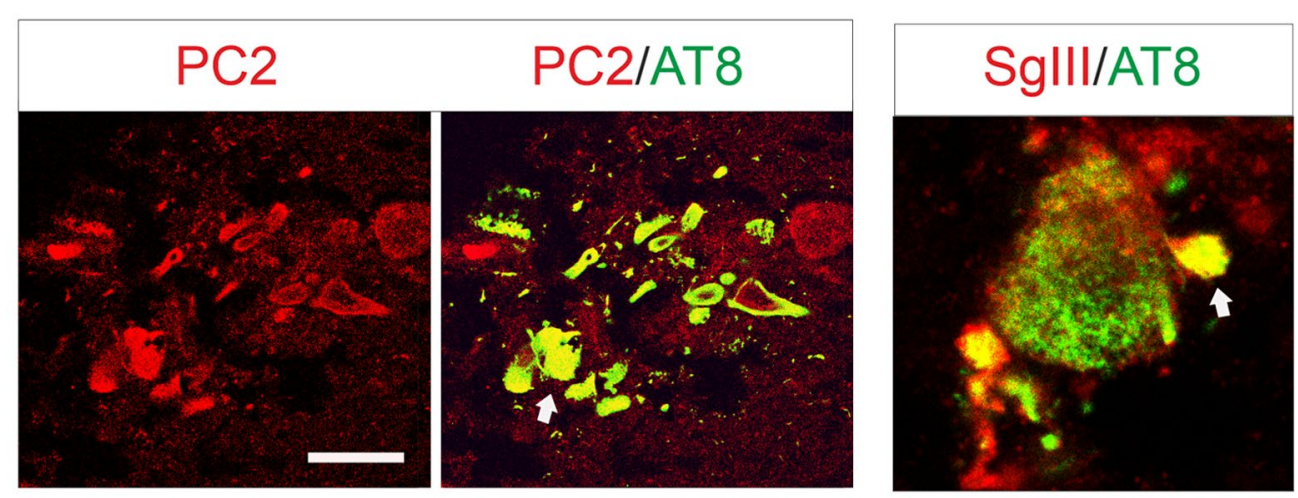

C
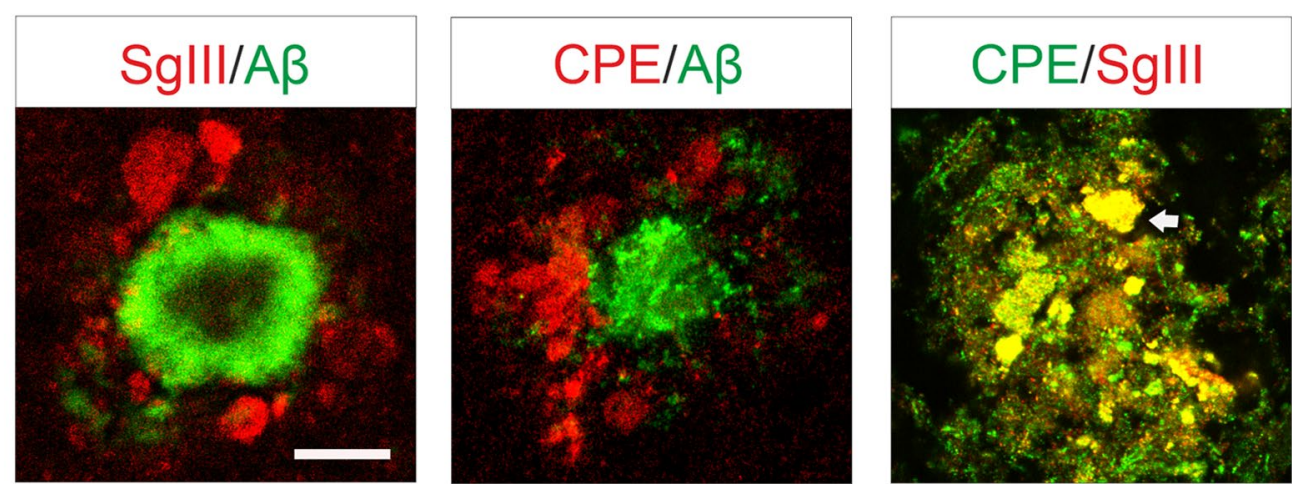

Fig. 3 Distribution of secretory proteins in the AD cerebral cortex. a Representative peroxidase immunohistochemistry for different secretory proteins in senile plaques at the superficial layers of the AD parietal cortex. Dystrophic neurite-like structures are indicated by arrows. Scale bar $20 \mu \mathrm{m}$. b In the same cortical senile plaques, AT8 immunofluorescence reveals PC2 ${ }^{+}$and Sglll aberrant structures as dystrophic neurites. Arrows indicate colocalization in yellow. Scale bar, $20 \mu \mathrm{m}$. c Three different double immunofluorescence images showing focal $A \beta^{+}$deposit surrounded by positive SgIII and CPE accumulations and the presence of Sglll and CPE in the same aberrant structures. Arrows indicate colocalization in yellow. Scale bar $20 \mu \mathrm{m}$

substantiated the neuropathological identity of these large granules (Fig. 4b). Mander's correlation coefficient for CK1 $\delta$ overlapping with PC2 was $0.55 \pm 0.13$ and for PC2 overlapping with CK1 $\delta$ was $0.62 \pm 0.20(n=12)$, whereas Mander's coefficient for CHMP2B overlapping with $\mathrm{PC} 1 / 3$ was $0.43 \pm 0.25$ and for $\mathrm{PC} 1 / 3$ overlapping with CHMP2B was $0.54 \pm 0.28(n=10)$. These values indicate good colocalization between DCV proteins and GVD bodies in the AD hippocampus. Additionally, an atypical colocalization of $\mathrm{PC} 2$ and $\mathrm{PC} 1 / 3$ with the lysosomal marker LAMP1 was also detected in GVD bodies (Fig. 4b). Interestingly, the PC2- and PC1/3immunolabelled GVD inclusions were associated with neurofibrillary tangle pathology in AD samples (Fig. 4c, d). Most pyramidal neurons displaying GVD bodies positive for PC2 (81\%) and PC1/3 (77\%) also contained hyperphosphorylated tau $\left(\mathrm{AT}^{+}\right)$. Although the GVD inclusions positive for DCV proteins were detected in 
a

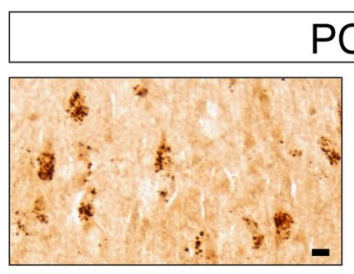

b
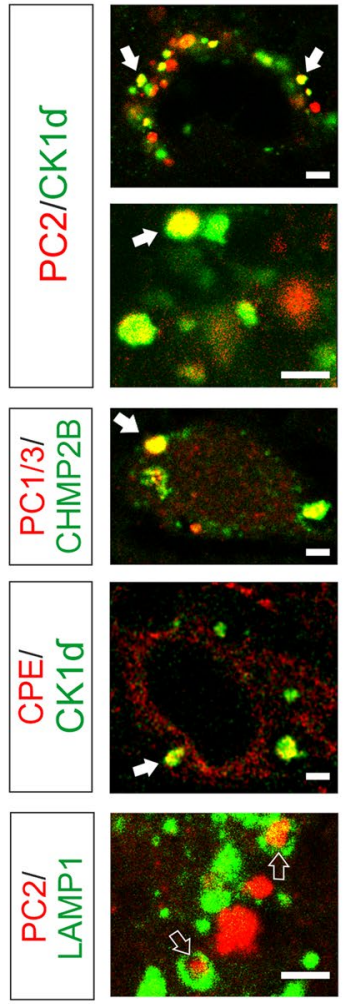
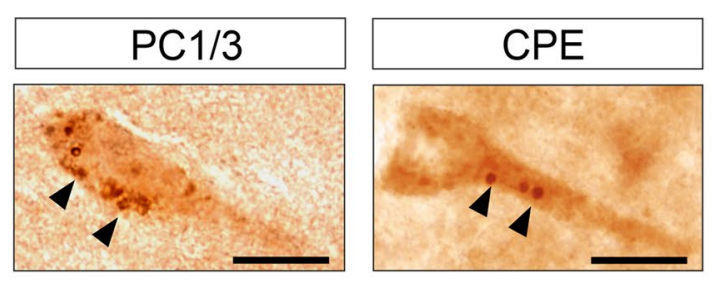

C
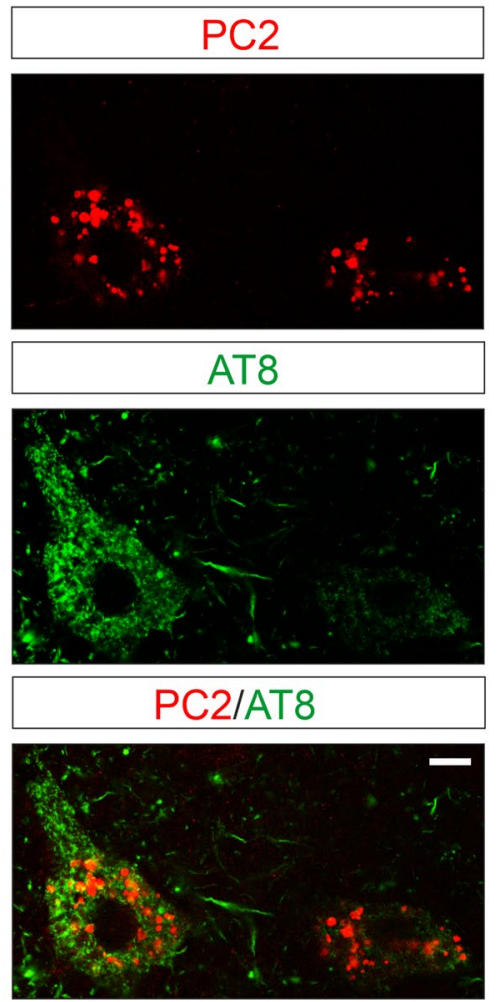

d
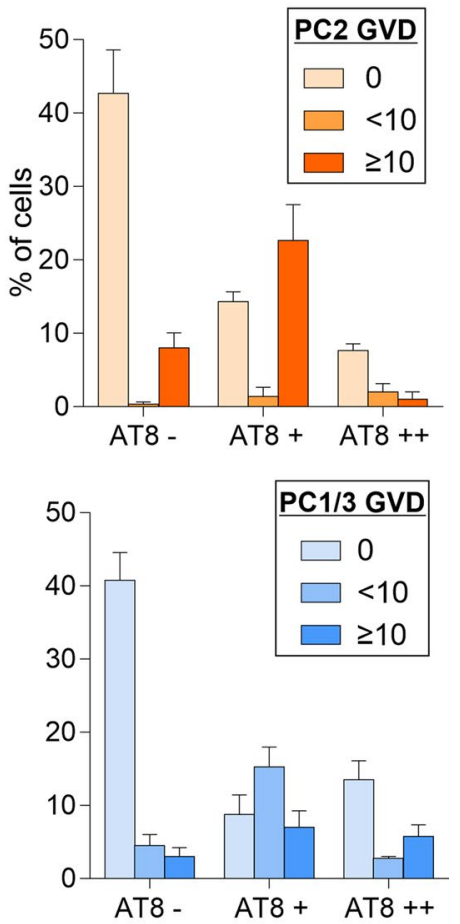

Fig. 4 DCV proteins are accumulated in GVD bodies in CA1 pyramidal neurons of AD patients. a Peroxidase immunolabelling shows PC2, PC1/3 and CPE accumulations in aberrant granules (arrowheads) located in CA1 pyramidal neurons of AD hippocampus. Scale bars, $10 \mu$ m. $\mathbf{b}$ PC2, PC1/3 and CPE colocalization with the markers of GVD bodies CK1 $\delta$ and CHMP2B (arrows) and the presence of lumenal PC2 and the transmembrane LAMP1 in the same AD granule (open-arrows) in different neuronal cell bodies of AD cases. Scale bars, $2 \mu \mathrm{m}$. c PC2 ${ }^{+}$GVD inclusions are found either in mature $\left(\mathrm{AT}^{++}{ }^{+}\right.$) (cell at left) or in undeveloped $\left(\mathrm{AT}^{+}\right)$(cell at right) neurofibrillary tangles in CA1 pyramidal neurons of an AD case. Scale bar, $7 \mu \mathrm{m}$. d Graphs showing the percentages of cells displaying absent (0), few (<10), or many ( $\geq 10)$ PC2- and PC1/3-labelled GVD in AD cases, depending on the occurrence of neurofibrillary tangles (negligible, AT8 ${ }^{-}$; low, AT $^{+}$, strong, AT8 ${ }^{++}$)

neurons containing mature neurofibrillary tangles, the DCV-labeled aberrant granules were more often present in early-stages of neurofibrillary tangle formation (Fig. 4c, d).

Taken together, these results show that an aberrant accumulation of DCV components is associated with two neuropathological hallmarks of the $\mathrm{AD}$ cerebral cortex, plaque-related dystrophic neurites and GVD bodies.
Decreased levels of secretory DCV cargos in CSF from AD patients are associated with neurodegeneration markers Next, we investigated the levels of DCV proteins in 66 CSF samples from phenotypically well-characterized AD patients $(n=33)$ and cognitively normal controls $(n=33)$ with immunoblotting and radioimmunoassay methods. No differences in the CSF total protein content were found between $\mathrm{AD}$ and controls, either by Bradford assay or Coomassie staining of SDS-PAGE gels (Fig. 5a). However, levels of most molecular forms of DCV proteins were decreased in the CSF from AD patients compared with those from cognitively normal controls (Figs. 5b 

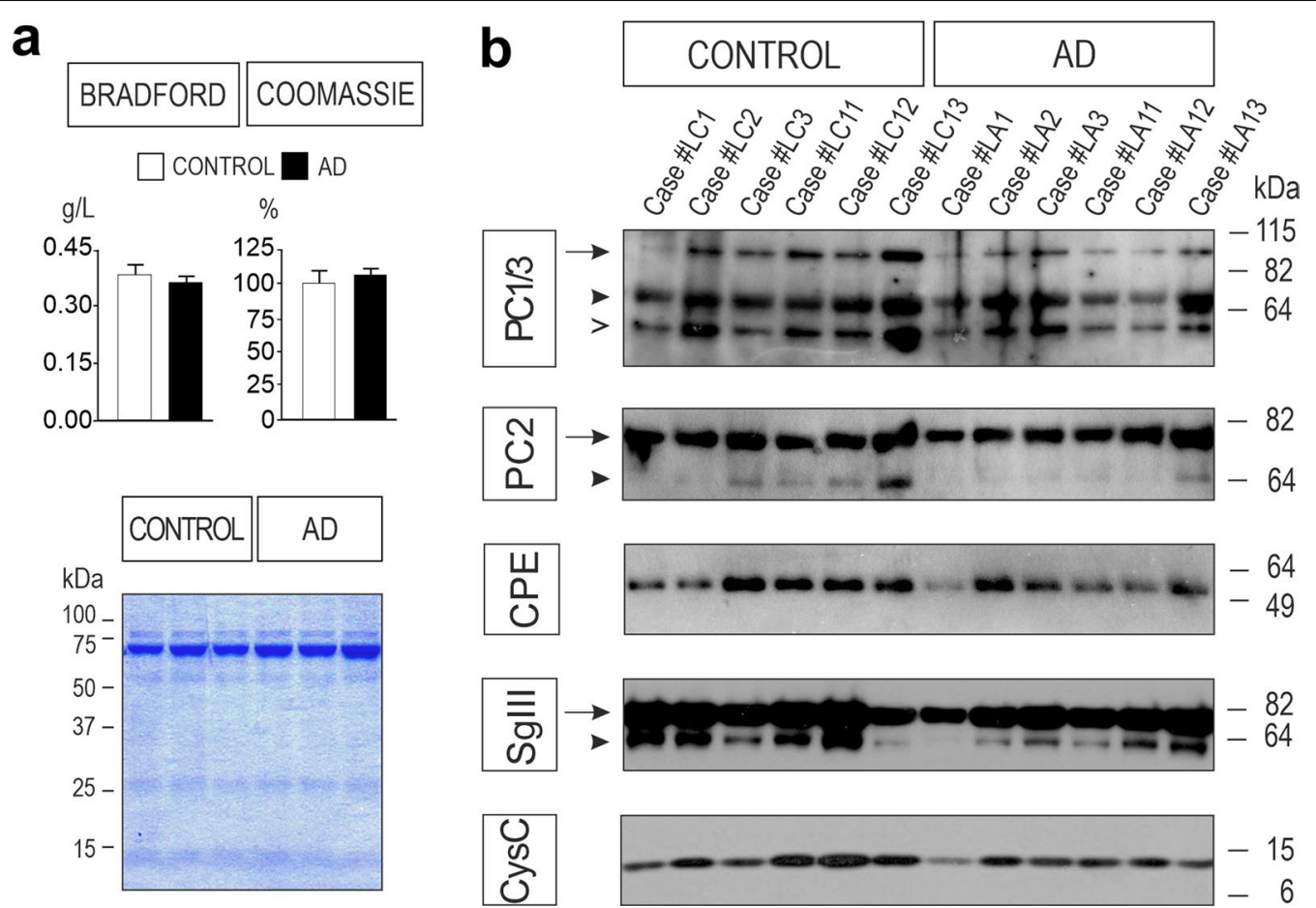

Fig. 5 Western blot analysis of secretory proteins in the CSF of AD patients. a Total protein content in control and AD CSF samples was determined by Bradford assay and Coomassie staining of SDS-PAGE gels. b Representative immunoblots show levels of PC1/3, PC2, CPE, Sglll, and CysC in the same control or AD CSF samples. Arrows and arrowheads indicate unprocessed and mature protein forms, respectively, and the symbol > points to a lower-electrophoretic-mobility form

and 6). Representative immunoblots for different secretory proteins of the same $\mathrm{AD}$ and non- $\mathrm{AD}$ individuals are illustrated in Fig. 5b. The most prominent reduction in $\mathrm{AD}$ was found for unprocessed $\mathrm{PC} 1 / 3(-42 \% \pm 5.7 \%$, $P=0.0003)$. Although levels of the mature form were apparently lower in $\mathrm{AD}$, they did not reach statistical significance $(P=0.075)$ (Fig. 6). When we quantified the levels of mature and unprocessed forms of PC1/3 together, a significant decrease was detected in the $\mathrm{AD}$ group $(-24 \%, P=0.03)$. Consistently, we also detected an apparent $\mathrm{PC} 1 / 3$ cleaved form displaying a lower electrophoretic mobility identified by the polyclonal antibodies used in this study. When analyzing this molecular species together with the other two bands, we found decreased levels of total $\mathrm{PC} 1 / 3$ in the CSF from AD patients compared to controls $(P=0.05)$. In addition, each of the two bands detected by PC2 antibodies that represent precursor and mature forms, was statistically decreased in $\mathrm{AD}$ samples $(-16 \%, P=0.024$ and $-12 \%, P=0.011$, respectively; Fig. 6), as well as in a pooled quantification $(-18 \%$, $P=0.0009$ ). The DCV-contained exopeptidase CPE was reduced by $\sim 20 \%$ in the CSF of the patient cohort $(P=0.016)$. Regarding members of the granin family, the most abundant form of SgIII in the CSF, proSgIII, was decreased in $\mathrm{AD}(P=0.047)$, whereas no significant differences were detected for the processed protein. An analysis of the two forms showed no differences between $\mathrm{AD}$ and non-AD individuals $(P=0.612)$. We also determined the CSF levels of SgII/secretoneurin with an radioimmunoassay assay. No statistical differences were found between $\mathrm{AD}$ and control groups. Finally, a reduction of about 33\% was observed for the secretory protein CysC in the CSF of AD patients $(P=0.001)$.

To investigate the possible relationships of secretory protein forms with age, cognitive status (MMSE), and the core CSF biomarkers of $\mathrm{AD}\left(\mathrm{A} \beta_{1-42}, \mathrm{P}\right.$-tau and $\mathrm{T}$-tau), Spearman correlation analysis was carried out in the AD cohort (33 individuals) (Fig. 7). No molecular forms of secretory proteins were significantly correlated with age or $\mathrm{A} \beta_{1-42}$ (Fig. 7). In contrast, we detected strong correlations, positive between the mature PC2 form and MMSE score $(P=0.0001, r=0.6449)$ and inverse between PC2 and T-tau $(P=0.0004, r=-0.5837)$, applying Bonferroni correction. Non-corrected analysis further evidenced an inverse correlation of P-tau with PC2 and PC1/3 and T-tau with $\mathrm{PC} 1 / 3$, and a direct correlation of MMSE with $\mathrm{PC} 1 / 3$. Additionally, corrected analysis evidenced positive correlations between levels of P-tau and CPE $(P=0.0013, r=0.5377)$ and the precursor form of SgIII $(P=0.0019, r=0.5216)$, whereas non-corrected analysis 

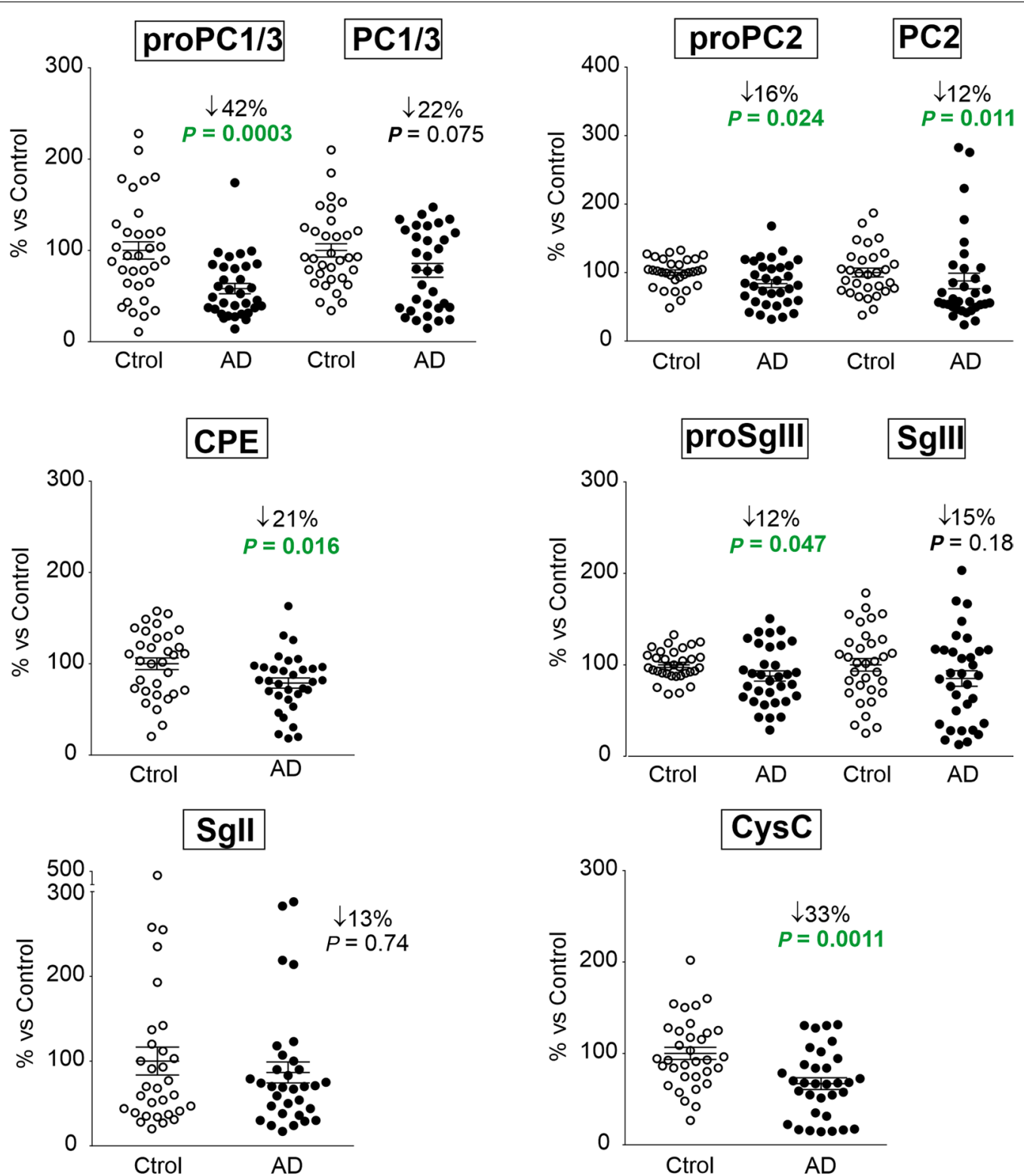

Fig. 6 CSF samples from AD patients display decreased levels of secretory proteins. PC1/3, PC2, CPE, Sglll and CysC were analyzed with Western blot and Sgll with radioimmunoassay. Scatter dot-plots represent percent variation of secretory protein levels in the CSF of AD patients ( $n=33$ ) compared to controls $(n=33)$. Data are presented as the mean \pm SEM of analysis. Statistically significant difference was calculated using a two-tailed Mann-Whitney test

showed a direct correlation of levels of CPE, CysC and different forms of SgIII with P-tau and T-tau (Fig. 7).

\section{Discussion}

The present findings show that the levels of neuronal prohormone convertases and other DCV proteins decrease in the CSF of AD patients, and that this decrease correlates both with the cognitive impairment status and with established CSF neurodegenerative markers. In AD brains, these proteins accumulate in plaque-surrounding dystrophic neurites and reactive astroglia, whereas PC1/3, PC2 and CPE are also remarkably accumulated in hippocampal GVD bodies.

In contrast to the global loss of major SV components (e.g. Syp and Rab3A) [53, 54], we show that the total levels of DCV proteins remain mostly invariable in the cerebral cortex of $\mathrm{AD}$ patients. Only proPC2 shows a reliable increase in AD samples, mainly in the hippocampus. 


\begin{tabular}{|c|c|c|c|c|c|c|c|c|c|c|c|c|c|c|c|c|}
\hline \multirow[t]{2}{*}{ vs CSF } & \multicolumn{2}{|c|}{ proPC1/3 } & \multicolumn{2}{|c|}{$P C 1 / 3$} & \multicolumn{2}{|c|}{ proPC2 } & \multicolumn{2}{|c|}{$P C 2$} & \multicolumn{2}{|c|}{ CPE } & \multicolumn{2}{|c|}{ prosglll } & \multicolumn{2}{|c|}{ Sglll } & \multicolumn{2}{|c|}{ CysC } \\
\hline & $r$ & $P$ & $r$ & $P$ & $r$ & $P$ & $r$ & $P$ & $r$ & $P$ & $r$ & $P$ & $r$ & $P$ & $r$ & $P$ \\
\hline Age & 0.3137 & 0.0754 & 0.1852 & 0.3023 & 0.0635 & 0.7255 & 0.3436 & 0.0503 & -0.2393 & 0.1798 & -0.1280 & 0.4778 & -0.0348 & 0.8477 & -0.1156 & 0.5216 \\
\hline MMSE & 0.3143 & 0.0749 & 0.4416 & 0.0101 & -0.0517 & 0.7751 & 0.6449 & 0.0001 & -0.1387 & 0.4413 & 0.0072 & 0.9681 & 0.1911 & 0.2867 & -0.1197 & 0.5070 \\
\hline $\begin{array}{c}\text { CSF } \\
A \beta 42\end{array}$ & -0.1945 & 0.2781 & 0.0239 & 0.8949 & -0.1542 & 0.3914 & 0.2200 & 0.2186 & 0.0676 & 0.7086 & 0.1300 & 0.4709 & 0.2595 & 0.1448 & 0.1489 & 0.4083 \\
\hline $\begin{array}{c}\text { CSF } \\
\text { T-tau }\end{array}$ & -0.1896 & 0.2905 & -0.4942 & 0.0035 & 0.0836 & 0.6438 & -0.5837 & 0.0004 & 0.4717 & 0.0056 & 0.4326 & 0.0119 & 0.3010 & 0.0887 & 0.3714 & 0.0333 \\
\hline $\begin{array}{c}\text { CSF } \\
\text { P-tau }\end{array}$ & -0.0675 & 0.7089 & -0.3660 & 0.0362 & 0.2094 & 0.2421 & -0.4369 & 0.0110 & 0.5377 & 0.0013 & 0.5216 & 0.0019 & 0.4217 & 0.0145 & 0.2905 & 0.1010 \\
\hline
\end{tabular}

PC2 vs MMSE

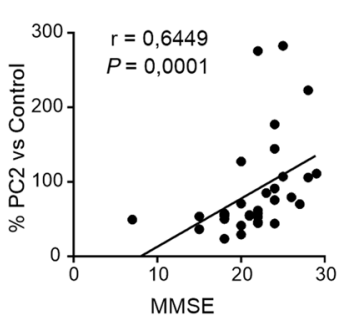

PC2 vs T-TAU

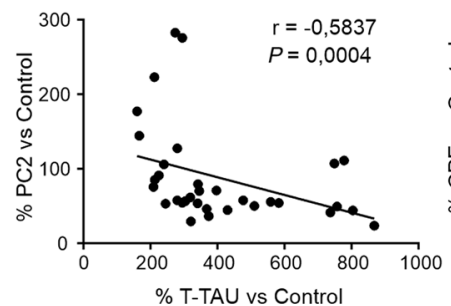

CPE vs P-TAU

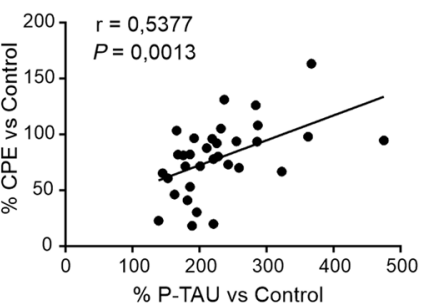

proSglll vs P-TAU

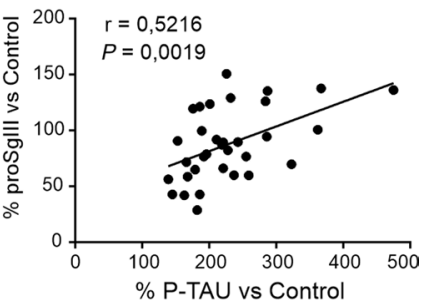

Fig. 7 Correlation analysis of CSF secretory proteins with age, cognitive performance, and core CSF biomarkers in AD subjects. Top Table summarizing Bonferroni-corrected Spearman correlations of secretory protein forms with age, MMSE score, A $\beta 1-42$, P-tau, and T-tau. Significant correlations $(P<0.0019)$ are highlighted in green. Non-corrected significant correlations $(P<0.05)$ are highlighted in yellow. Bottom Significant correlations are represented in scatter plots

These observations support our previous data by Plá et al. [45] on SgIII and CPE, but differ from others [25, 52, 55]. Yakovleva et al. [55] have reported an increase in the PC2 form in AD parietal cortex, whereas no changes of PC1/3 and $\mathrm{PC} 2$ or decrease of $\mathrm{PC} 1 / 3$ has been shown in the injured frontal cortex $[25,52]$. Because SV markers are virtually restricted to presynaptic terminals, their global alterations likely reflect variations in synaptic contacts. However, the broad distribution of DCV proteins makes it impossible to associate their total levels with synaptic changes. In fact, in situ immunodetection (Figs. 2, 3, 4) reveals dramatic alterations of these markers at cellular and subcellular levels that are hidden in global analyses (Fig. 1 and Additional file 1: Fig. S2).

In the $\mathrm{AD}$ cerebral cortex, we found no apparent changes in DCV proteins in normal-shaped axons and terminal-like buttons. However, we detected accumulations of DCV cargos in somata and projections of neurons and astrocytes associated with the degenerative and inflammatory progression of the disease. Remarkably, we detected deposits of DCV components (mainly PC2 and $\mathrm{PC} 1 / 3$ ) in GVD bodies in pyramidal neurons in AD brain. These inclusions are believed to be aberrant lysosomes, exhibiting a central dense core, located in neurons of hippocampus and other brain areas in patients with different primary tauopathies, especially in $\mathrm{AD}$ [56-58]. Our results showing LAMP1-surrounded $\mathrm{PC}^{+}$inclusions in cells that contain immature neurofibrillary tangles are consistent with the idea that the emergence of GVD granules precedes the appearance of fully-formed tangles in degenerating neurons [56]. To our knowledge, the present study is the first to provide evidence of a DCV cargo in these neuropathological granules. A plethora of proteins has been identified in GVD bodies [56, 59-61], including cytoskeletal components and proteins of the unfolded protein response, autophagic and transduction pathways, cell stress and apoptosis, the necrosome complex, and the RNA-binding proteins, but not DCV components. Therefore, our results involve the regulated secretory pathway in AD-related GVD. This is supported by reports showing the presence of the SV protein TMEM230, the Golgi apparatus Golgin A4, and components of the endoplasmic reticulum unfolded protein response in GVD bodies [56, 61-63]. Because in addition to the hippocampus, the parietal cortex can also display GVD [58], our results of elevated levels of the precursor form of $\mathrm{PC} 2$ in $\mathrm{AD}$ homogenates point to non-processed PC2 as the main form in GVD bodies, which may be related to the high tendency of proPC2 to form large aggregates [64]. 
Another neuronal degenerative structure displaying prominent alteration of DCV cargos is the dystrophic neurite. Since the report of striking amounts of $\mathrm{CgA}$ in AD dystrophic neurites, almost every DCV marker has been detected as accumulating in these degenerative structures, including transmitter cargos (e.g. BDNF) and intrinsic molecular machinery (i.e. granin family members) but not SV components [22, 45, 50, 54, 65-67]. In this study, we show the previously unrevealed accumulation of $\mathrm{PC} 1 / 3$ and $\mathrm{PC} 2$ in amyloid-surrounding dystrophic neurites. Thus, dystrophic neurites are a significant location for DCV retention. The recent work of Sadleir et al. [68] showing a dramatic microtubule and trafficking disruption in dystrophic neurites associated with amyloid plaques strongly substantiates the aberrant accumulation of DCVs in these swollen structures and, therefore, suggests an important impairment in their vesicular cargo release. Lastly, in addition to the neuronal changes, the increased immunostaining of SgIII and $\mathrm{CysC}$ in peri-plaque astrocytes is consistent with previous studies and likely corresponds with transcriptional changes in activated cells and/or an A $\beta$-induced deficiency in glial secretion $[29,33,45,51,69]$.

In the CSF of AD patients, we detected that five out of the six analyzed proteins are significantly lowered compared with controls. Decreased levels of PC1/3, PC2 and SgIII have very recently been found in large-scale proteomic CSF screens from AD patients, but this has not been immunologically verified yet [24, 70-74], whereas variable results for $\mathrm{CysC}, \mathrm{CPE}$ and SgII have been obtained [24, 71, 75-78]. In general, decreased levels of different DCV cargos (i.e. CgA, VGF and 7B2) have been found in AD CSF, with only a few reports showing opposing results $[26,78]$. Several explanations might be offered for these discrepancies. First, the work of Duits et al. [78], illustrating high levels of CgA, SgII and VGF in CSF of patients with mild cognitive impairment progressing to $\mathrm{AD}$, suggests that early events in the $\mathrm{AD}$ pathophysiological cascade can display opposite changes in DCV cargos in later stages. This agrees with earlier studies showing that the synaptic decline in early stages of AD is compensated by an increase in synaptic size of the remaining contacts [5]. Therefore, failure in peptidergic neurotransmission, presumably occurring in dystrophic neurites, could trigger compensatory production of DCVs in unaffected terminals. In addition, taking into account that cargos such as CPE, SgIII and CysC are robustly produced by neurons and non-neuronal cells, CSF levels could depend on the balance between neuronal impairment and glial activation in different AD stages.

Since the CSF likely reflects the composition of the extracellular milieu in the central nervous system, decreased levels of secretory proteins in the CSF of patients could contribute to the pathophysiology of the disease. Based on experimental evidence, low levels of neuroactive peptides, such as VGF and BDNF, may contribute to memory and cognitive impairments, whereas decreased levels of $\mathrm{Cys} C$ and the prohormone convertase-binding proteins $7 \mathrm{~B} 2$ and proSAAS could promote amyloidogenesis [34, 66, 67, 79, 80]. Several mechanisms may be put forward to underlie the occurrence of low concentrations of secretory proteins in AD CSF. Although alterations in the blood-brain barrier and in extracellular peptide degradation cannot be ruled out, both transcriptional changes and release impairments may underlie the decline of secretory components in AD CSF [25, 33, 68, 81-83]. Additionally, the decreased levels of DCV proteins in AD CSF may reflect the synaptic and neuronal loss occurring in the disease. The present results of robust inverse correlation of the neuronal prohormone convertases with tauopathy markers and cognitive impairment strongly suggest that the reduced levels of these DCV cargos correspond with the spreading neural damage. Conversely, the levels of proteins expressed by both neurons and astrocytes (e.g. SgIII) directly correlate with neurodegeneration markers in $\mathrm{AD}$. Within the $\mathrm{AD}$ cohort, besides impairment of the neuronally produced forms, it is conceivable that production of secretory proteins by activated astrocytes increases as neuronal damage worsens $[29,45,51,69]$. Furthermore, the connection of secretory proteins with neurodegeneration, but not with amyloid plaque pathology, is consistent with recent proteomic studies in non-AD neurodegenerative diseases, such as frontotemporal dementia, where a decline of $\mathrm{CgA}, \mathrm{VGF}$ and CysC occurs in the CSF of patients [84-86].

The current diagnosis methods for $\mathrm{AD}$ include cognitive tests, neuroimaging techniques and CSF assays. However, there is still no clinical strategy available for the precise and early detection of $\mathrm{AD}$. Some limitations involve disease heterogeneity, co-morbidities and overlapping between different neurodegenerative disorders [87]. Among new potential biomarkers, those that monitor synaptic alterations are needed for prognosis of disease progression and evaluation of effects of drugs on $\mathrm{AD}$ [88]. Because the altered DCV proteins in CSF have been implicated in synaptopathies beyond neurodegenerative diseases, such as delirium and schizophrenia [89, 90], DCV cargos could be used as complementary biomarkers to follow synaptic dysfunction and loss and neurodegeneration in $\mathrm{AD}$. 


\section{Conclusions}

The current results show alterations of DCV cargos belonging to regulated secretory pathways, in the CSF and cortical tissues of $\mathrm{AD}$ patients. Because neuronspecific $\mathrm{PC} 1 / 3$ and $\mathrm{PC} 2$ are associated with tauopathy and cognitive impairment, we propose these proteins as complementary biomarker candidates for tracking ADassociated synaptic dysfunction and neurodegeneration.

\begin{abstract}
Abbreviations
$A \beta$ : Amyloid- $\beta$; AD: Alzheimer's disease; BDNF: Brain-derived neurotrophic factor; Cg: Chromogranin; CHMP2B: Charged Multivesicular Body Protein 2B; CK1 8 : Casein kinase 1 delta; CPE: Carboxypeptidase E; CSF: Cerebrospinal fluid; CysC: Cystatin C; DCV: Dense core vesicle; GFAP: Glial fibrillary acidic protein; GVD: Granulovacuolar degeneration; LAMP-1: Lysosomal associated membrane protein 1; MMSE: Mini-mental state examination; PBS: Phosphate buffered saline; PC: Prohormone convertase; TMEM230: Transmembrane protein 230; TREM2: Triggering receptor expressed on myeloid cells 2; P-tau: Phosphorylated tau; T-tau: Total tau; Sg: Secretogranin; SNAP-25: Synaptosomal-associated protein of 25 kDa; Syp: Synaptophysin; SV: Synaptic vesicle; VGF: The nerve growth factor inducible protein VGF.
\end{abstract}

\section{Supplementary Information}

The online version contains supplementary material available at https://doi. org/10.1186/s40035-021-00263-0.

Additional file 1: Fig. S1. Brain secretory proteins are abundantly detected in human CSF. Fig. S2. Levels of secretory proteins in the AD parietal cortex. Fig. S3. Levels and distribution of CysC in the AD parietal cortex. Table S1. List of used primary antibodies.

\section{Acknowledgements}

We are grateful to Dr I. Lindberg (University of Maryland) for providing us with PC2 antibodies and for valuable comments on the manuscript. We also acknowledge Dr T. Fernández (Universidad Rey Juan Carlos) and J. PérezClausell (University of Barcelona) for helpful discussions and Laia Muñoz and Soraya Torres for technical assistance. We thank Tom Yohannan and Patrick Carlin for editorial help.

\section{Authors' contributions}

FA, AL and IF conceived and designed the study. All authors contributed to data acquisition and analysis. FA drafted the manuscript and all authors revised and completed the paper. All authors have read and approved the final manuscript.

\section{Funding}

This work was supported by grants from the Spanish Ministry of Economy and Competitiveness (BFU2016-80868-R, MINECO/FEDER, to FA), the Spanish Ministry of Science and Innovation (PID2019-107738RB-I00, MICINN/FEDER, to FA), the Catalonian Government (2017SGR1255 to FA, 2014SGR-0235 to AL, PERIS SLT006/17/125 to DA), the Carlos III Institute of Health, Spain (PI18/00435 to DA, PI14/1561 and PI17/01896 to AL) and the CIBERNED program (Program 1, Alzheimer Disease to AL and IF), partly funded by Fondo Europeo de Desarrollo Regional (FEDER), Unión Europea, "Una manera de hacer Europa”, and BBVA Foundation (to AL). We are grateful to the Generalitat de Catalunya (NB), the Ministry of Education and Vocational Training (NB) and the Universitat de Barcelona (VP) for financial support.

\section{Availability of data and materials}

All data generated or analyzed during this study are included in this article and its supplementary materials.

\section{Declarations}

\section{Ethics approval and consent to participate}

The study was performed according to the ethical principles of the Declaration of Helsinki and was approved by the local ethics committees.

\section{Consent for publication}

Not applicable.

\section{Competing interests}

The authors declare that they have no competing interests.

\section{Author details}

${ }^{1}$ Department of Cell Biology, Physiology and Immunology, Faculty of Biology, University of Barcelona, 08028 Barcelona, Spain. ${ }^{2}$ Institute of Neurosciences, University of Barcelona, 08028 Barcelona, Spain. ${ }^{3}$ Memory Unit, Department of Neurology, Sant Pau Biomedical Research Institute. Sant Pau Hospital, Autonomous University of Barcelona, 08041 Barcelona, Spain. ${ }^{4}$ Center for Networked Biomedical Research on Neurodegenerative Diseases (CIBERNED), 28031 Madrid, Spain. ${ }^{5}$ Department of Pharmacology, Innsbruck Medical University, 6020 Innsbruck, Austria. ${ }^{6}$ Department of Pathology and Experimental Therapeutics, University of Barcelona, and Bellvitge University Hospital, Bellvitge Biomedical Research Institute, Hospitalet de Llobregat, Spain. ${ }^{7}$ Present Address: Center for Translational Neuromedicine, University of Rochester Medical Center, Rochester, NY 14642, USA.

Received: 25 February 2021 Accepted: 14 September 2021

Published online: 26 September 2021

\section{References}

1. Scheltens P, Blennow K, Breteler MMB, de Strooper B, Frisoni GB, Salloway S, et al. Alzheimer's disease. Lancet. 2016;388:505-17.

2. Canter RG, Penney J, Tsai LH. The road to restoring neural circuits for the treatment of Alzheimer's disease. Nature. 2016;539:187-96.

3. Molinuevo JL, Ayton S, Batrla R, Bednar MM, Bittner T, Cummings J, et al. Current state of Alzheimer's fluid biomarkers. Acta Neuropathol. 2018:136:821-53.

4. Zetterberg H, Bendlin BB. Biomarkers for Alzheimer's disease-preparing for a new era of disease-modifying therapies. Mol Psychiatry. 2021;26:296-308

5. DeKosky ST, Scheff SW. Synapse loss in frontal cortex biopsies in Alzheimer's disease: correlation with cognitive severity. Ann Neurol. 1990;27:457-64.

6. Terry RD, Masliah E, Salmon DP, Butters N, DeTeresa R, Hill R, et al. Physical basis of cognitive alterations in alzheimer's disease: Synapse loss is the major correlate of cognitive impairment. Ann Neurol. 1991;30:572-80.

7. Forner S, Baglietto-Vargas D, Martini AC, Trujillo-Estrada L, LaFerla FM. Synaptic impairment in Alzheimer's Disease: a dysregulated symphony. Trends Neurosci. 2017:40:347-57.

8. DeTure MA, Dickson DW. The neuropathological diagnosis of Alzheimer's disease. Mol Neurodegener. 2019;14:32.

9. Olsson B, Lautner R, Andreasson U, Öhrfelt A, Portelius E, Bjerke M, et al. CSF and blood biomarkers for the diagnosis of Alzheimer's disease: a systematic review and meta-analysis. Lancet Neurol. 2016;15:673-84.

10. Suárez-Calvet M, Kleinberger G, Araque Caballero MÁ, Brendel M, Rominger A, Alcolea D, et al. sTREM2 cerebrospinal fluid levels are a potential biomarker for microglia activity in early-stage Alzheimer's disease and associate with neuronal injury markers. EMBO Mol Med. 2016;8:466-76

11. Craig-Schapiro R, Perrin RJ, Roe CM, Xiong C, Carter D, Cairns NJ, et al. YKL40: a novel prognostic fluid biomarker for preclinical Alzheimer's disease. Biol Psychiatry. 2010;68:903-12.

12. Bolós M, Llorens-Martín M, Jurado-Arjona J, Hernández F, Rábano A, Avila J. Direct evidence of internalization of Tau by microglia in vitro and in vivo. J Alzheimers Dis. 2016;50:77-87.

13. Querol-Vilaseca M, Colom-Cadena M, Pegueroles J, San Martín-Paniello C, Clarimon J, Belbin O, et al. YKL-40 (Chitinase 3-like I) is expressed in 
a subset of astrocytes in Alzheimer's disease and other tauopathies. J Neuroinflammation. 2017;14:118.

14. Brinkmalm A, Brinkmalm G, Honer WG, Frölich L, Hausner L, Minthon L, et al. SNAP-25 is a promising novel cerebrospinal fluid biomarker for synapse degeneration in Alzheimer's disease. Mol Neurodegener. 2014;9:53.

15. Mattsson N, Insel PS, Palmqvist S, Portelius E, Zetterberg H, Weiner M, et al. Cerebrospinal fluid tau, neurogranin, and neurofilament light in Alzheimer's disease. EMBO Mol Med. 2016;8:1184-96.

16. Lewczuk P, Riederer P, O'bryant SE, Verbeek MM, Dubois B, Visser PJ, et al. Cerebrospinal fluid and blood biomarkers for neurodegenerative dementias: an update of the Consensus of the Task Force on Biological Markers in Psychiatry of the World Federation of Societies of Biological Psychiatry. World J Biol Psychiatry. 2017:19:244-328.

17. Lleó A, Núñez-Llaves R, Alcolea D, Chiva C, Balateu-Paños D, ColomCadena $\mathrm{M}$, et al. Changes in synaptic proteins precede neurodegeneration markers in preclinical Alzheimer's disease cerebrospinal fluid. Mol Cell Proteomics. 2019;18:546-60.

18. van den Pol AN. Neuropeptide transmission in brain circuits. Neuron. 2012;76:98-115.

19. Verkhratsky A, Matteoli M, Parpura V, Mothet J-P, Zorec R. Astrocytes as secretory cells of the central nervous system: idiosyncrasies of vesicular secretion. EMBO J. 2016;35:239-57.

20. van de Bospoort R, Farina M, Schmitz SK, de Jong A, de Wit H, Verhage M, et al. Munc13 controls the location and efficiency of dense-core vesicle release in neurons. J Cell Biol. 2012;199:883-91.

21. Persoon CM, Moro A, Nassal JP, Farina M, Broeke JH, Arora S, et al. Pool size estimations for dense-core vesicles in mammalian CNS neurons. EMBO J. 2018;37:e99672.

22. Weiler $\mathrm{R}$, Lassmann $\mathrm{H}$, Fischer $\mathrm{P}$, Jellinger $\mathrm{K}$, Winkler $\mathrm{H}$. A high ratio of chromogranin A to synaptin/synaptophysin is a common feature of brains in Alzheimer and Pick disease. FEBS Lett. 1990;263:337-9.

23. Blennow K, Davidsson P, Wallin A, Ekman R. Chromogranin A in cerebrospinal fluid: a biochemical marker for synaptic degeneration in Alzheimer's disease? Dement Geriatr Cogn Disord. 1995;6:306-11.

24. Park SA, Jung JM, Park JS, Lee JH, Park B, Kim HJ, et al. SWATH-MS analysis of cerebrospinal fluid to generate a robust battery of biomarkers for Alzheimer's disease. Sci Rep. 2020;10:7423.

25. Bai B, Wang X, Li Y, Chen PC, Yu K, Dey KK, et al. Deep multilayer brain proteomics identifies molecular networks in Alzheimer's Disease progression. Neuron. 2020:105:975-91.

26. Pedrero-Prieto CM, García-Carpintero S, Frontiñán-Rubio J, LlanosGonzález E, Aguilera García C, Alcaín FJ, et al. A comprehensive systematic review of CSF proteins and peptides that define Alzheimer's disease. Clin Proteomics. 2020:17:21.

27. Wesenhagen KEJ, Teunissen CE, Visser PJ, Tijms BM. Cerebrospinal fluid proteomics and biological heterogeneity in Alzheimer's disease: a literature review. Crit Rev Clin Lab Sci. 2020;57:86-98.

28. Paco S, Margelí MA, Olkkonen VM, Imai A, Blasi J, Fischer-Colbrie R, et al. Regulation of exocytotic protein expression and $\mathrm{Ca}^{2+}$-dependent peptide secretion in astrocytes. J Neurochem. 2009;1 10:143-56.

29. Paco S, Pozas E, Aguado F. Secretogranin III is an astrocyte granin that is overexpressed in reactive glia. Cereb Cortex. 2010;20:1386-97.

30. Bartolomucci A, Possenti R, Mahata SK, Fischer-Colbrie R, Loh YP, Salton SRJ. The extended granin family: structure, function, and biomedical implications. Endocr Rev. 2011;32:755-97.

31. Hoshino A, Lindberg I. Peptide biosynthesis: prohormone convertases $1 / 3$ and 2. Fricker LD, editor. Vol. 1, Colloquium Series on Neuropeptides Princeton, NJ: Morgan and Claypool Life Sciences Publishers; 2012. p. $1-112$.

32. Ji L, Wu HT, Qin $X Y$, Lan R. Dissecting carboxypeptidase E: properties, functions and pathophysiological roles in disease. Endocr Connect. 2017;6:18-38

33. Plá V, Barranco N, Pozas E, Aguado F. Amyloid- $\beta$ impairs vesicular secretion in neuronal and astrocyte peptidergic transmission. Front Mol Neurosci. 2017;10:1-15.

34. Mathews PM, Levy E. Cystatin C in aging and in Alzheimer's disease. Ageing Res Rev. 2016;32:38-50.

35. Wegrzyn JL, Bark SJ, Funkelstein L, Mosier C, Yap A, Kazemi-Esfarjani P, et al. Proteomics of dense core secretory vesicles reveal distinct protein categories for secretion of neuroeffectors for cell-cell communication. $J$ Proteome Res. 2010:9:5002-24.
36. Hyman BT, Phelps CH, Beach TG, Bigio EH, Cairns NJ, Carrillo MC, et al. National Institute on Aging-Alzheimer's Association guidelines for the neuropathologic assessment of Alzheimer's disease. Alzheimers Dement. 2012;8:1-13.

37. Alcolea D, Clarimón J, Carmona-Iraqui M, Illán-Gala I, Morenas-Rodríquez E, Barroeta I, et al. The Sant Pau Initiative on Neurodegeneration (SPIN) cohort: a data set for biomarker discovery and validation in neurodegenerative disorders. Alzheimers Dement TransI Res Clin Interv. 2019:5:597-609.

38. McKhann GM, Knopman DS, Chertkow H, Hyman BT, Jack CR, Kawas CH, et al. The diagnosis of dementia due to Alzheimer's disease: Recommendations from the National Institute on Aging-Alzheimer's Association workgroups on diagnostic guidelines for Alzheimer's disease. Alzheimers Dement. 2011;7:263-9.

39. Alcolea D, Vilaplana E, Pegueroles J, Montal V, Sánchez-juan P, Gonzálezsuárez $\mathrm{A}$, et al. Relationship between cortical thickness and cerebrospinal fluid YKL-40 in predementia stages of Alzheimer's disease. Neurobiol Aging. 2015:36:1-6.

40. Shen FS, Seidah NG, Lindberg I. Biosynthesis of the prohormone convertase PC2 in Chinese hamster ovary cells and in rat insulinoma cells. J Biol Chem. 1993;268:24910-5.

41. Kirchmair R, Hogue-Angeletti R, Gutierrez J, Fischer-Colbrie R, Winkler $H$. Secretoneurin-a neuropeptide generated in brain, adrenal medulla and other endocrine tissues by proteolytic processing of secretogranin II (chromogranin C). Neuroscience. 1993;53:359-65.

42. Lloyd DJ, Bohan S, Gekakis N. Obesity, hyperphagia and increased metabolic efficiency in PC1 mutant mice. Hum Mol Genet. 2006;15:1884-93.

43. Knoch KP, Nath-Sain S, Petzold A, Schneider H, Beck M, Wegbrod C, et al. PTBP1 is required for glucose-stimulated cap-independent translation of insulin granule proteins and Coxsackieviruses in beta cells. Mol Metab. 2014:3:518-30.

44. Hatanaka M, Tanabe K, Yanai A, Ohta Y, Kondo M, Akiyama M, et al. Wolfram syndrome 1 gene (WFS1) product localizes to secretory granules and determines granule acidification in pancreatic $\beta$-cells. Hum Mol Genet. 2011:20:1274-84.

45. Plá V, Paco S, Ghezali G, Ciria V, Pozas E, Ferrer I, et al. Secretory sorting receptors carboxypeptidase $\mathrm{E}$ and secretogranin III in amyloid $\beta$-associated neural degeneration in Alzheimer's disease. Brain Pathol. 2013;23:274-84.

46. Höring E, Harter PN, Seznec J, Schittenhelm J, Bühring HJ, Bhattacharyya $S$, et al. The "go or grow" potential of gliomas is linked to the neuropeptide processing enzyme carboxypeptidase $\mathrm{E}$ and mediated by metabolic stress. Acta Neuropathol. 2012;124:83-97.

47. Urbizu A, Canet-Pons J, Munoz-Marmol AM, Aldecoa I, Lopez MT, Compta $Y$, et al. Cystatin C is differentially involved in multiple system atrophy phenotypes. Neuropathol Appl Neurobiol. 2015;41:507-19.

48. Bjarnadottir M, Nilsson C, Lindström V, Westman A, Davidsson P, Thormodsson $F$, et al. The cerebral hemorrhage-producing cystatin $C$ variant (L68Q) in extracellular fluids. Amyloid. 2001;8:1-10.

49. Mi W, Jung SS, Yu H, Schmidt SD, Nixon RA, Mathews PM, et al. Complexes of amyloid- $\beta$ and cystatin $C$ in the human central nervous system. J Alzheimers Dis. 2009;18:273-80.

50. Kaufmann WA Barnas U, Humpel C, Nowakowski K, DeCol C, Gurka $P$, et al. Synaptic loss reflected by secretoneurin-like immunoreactivity in the human hippocampus in Alzheimer's disease. Eur J Neurosci. 1998;10:1084-94

51. Deng A, Irizarry MC, Nitsch RM, Growdon JH, Rebeck GW. Elevation of cystatin C in susceptible neurons in Alzheimer's disease. Am J Pathol. 2001;159:1061-8.

52. Winsky-Sommerer R, Grouselle D, Rougeot C, Laurent V, David JP, Delacourte $A$, et al. The proprotein convertase PC2 is involved in the maturation of prosomatostatin to somatostatin-14 but not in the somatostatin deficit in Alzheimer's disease. Neuroscience. 2003;122:437-47.

53. Sze Cl, Troncoso JC, Kawas C, Mouton P, Price DL, Martin $U$. Loss of the presynaptic vesicle protein synaptophysin in hippocampus correlates with cognitive decline in Alzheimer disease. J Neuropathol Exp Neurol. 1997;56:933-44.

54. Ferrer I, Martí E, Tortosa A, Blasi J. Dystrophic neurites of senile plaques are defective in proteins involved in exocytosis and neurotransmission. J Neuropathol Exp Neurol. 1998;57:218-25. 
55. Yakovleva T, Marinova Z, Kuzmin A, Seidah NG, Haroutunian V, Terenius L, et al. Dysregulation of dynorphins in Alzheimer disease. Neurobiol Aging. 2007:28:1700-8.

56. Köhler C. Granulovacuolar degeneration: a neurodegenerative change that accompanies tau pathology. Acta Neuropathol. 2016;132:339-59.

57. Wiersma VI, van Ziel AM, Vazquez-Sanchez S, Nölle A, Berenjeno-Correa E, Bonaterra-Pastra A, et al. Granulovacuolar degeneration bodies are neuron-selective lysosomal structures induced by intracellular tau pathology. Acta Neuropathol. 2019;138:943-70.

58. Thal DR, Del Tredici K, Ludolph AC, Hoozemans JJM, Rozemuller AJ, Braak $H$, et al. Stages of granulovacuolar degeneration: their relation to Alzheimer's disease and chronic stress response. Acta Neuropathol. 2011;122:577-89.

59. Caccamo A, Branca C, Piras IS, Ferreira E, Huentelman MJ, Liang WS, et al. Necroptosis activation in Alzheimer's disease. Nat Neurosci. 2017;20:1236-46.

60. Koper MJ, Van Schoor E, Ospitalieri S, Vandenberghe R, Vandenbulcke M, von Arnim CAF, et al. Necrosome complex detected in granulovacuolar degeneration is associated with neuronal loss in Alzheimer's disease. Acta Neuropathol. 2020;139:463-84.

61. Yamoah A, Tripathi P, Sechi A, Köhler C, Guo H, Chandrasekar A, et al. Aggregates of RNA binding proteins and ER chaperones linked to exosomes in granulovacuolar degeneration of the Alzheimer's disease brain. J Alzheimers Dis. 2020;75:139-56.

62. Kork F, Jankowski J, Goswami A, Weis J, Brook G, Yamoah A, et al. Golgin A4 in CSF and granulovacuolar degenerations of patients with Alzheimer disease. Neurology. 2018;91:e1799-808.

63. Siedlak SL, Jiang Y, Huntley ML, Wang L, Gao J, Xie F, et al. TMEM230 accumulation in granulovacuolar degeneration bodies and dystrophic neurites of Alzheimer's disease. J Alzheimers Dis. 2017;58:1027-33.

64. Lee SN, Lindberg I. 7B2 prevents unfolding and aggregation of prohormone convertase 2. Endocrinology. 2008;149:4116-27.

65. Ferrer I, Marín C, Rey MJ, Ribalta T, Goutan E, Blanco R, et al. BDNF and fulllength and truncated TrkB expression in Alzheimer disease. Implications in therapeutic strategies. J Neuropathol Exp Neurol. 1999;58:729-39.

66. Helwig M, Hoshino A, Berridge C, Lee SN, Lorenzen N, Otzen DE, et al. The neuroendocrine protein 7B2 suppresses the aggregation of neurodegenerative disease-related proteins. J Biol Chem. 2013;288:1114-24.

67. Hoshino A, Helwig M, Rezaei S, Berridge C, Eriksen JL, Lindberg I. A novel function for proSAAS as an amyloid anti-aggregant in Alzheimer's disease. J Neurochem. 2014;128:419-30.

68. Sadleir KR, Kandalepas PC, Buggia-Prévot V, Nicholson DA, Thinakaran G, Vassar R. Presynaptic dystrophic neurites surrounding amyloid plaques are sites of microtubule disruption, BACE1 elevation, and increased $A B$ generation in Alzheimer's disease. Acta Neuropathol. 2016;132:235-56.

69. Ying GX, Huang $\mathrm{C}$, Jiang ZH, Liu X, Jing NH, Zhou CF. Up-regulation of cystatin $C$ expression in the murine hippocampus following perforant path transections. Neuroscience. 2002;112:289-98.

70. Abdi F, Quinn JF, Jankovic J, McIntosh M, Leverenz JB, Peskind E, et al. Detection of biomarkers with a multiplex quantitative proteomic platform in cerebrospinal fluid of patients with neurodegenerative disorders. J Alzheimers Dis. 2006;9:293-348.

71. Perrin RJ, Craig-Schapiro R, Malone JP, Shah AR, Gilmore P, Davis AE, et al. Identification and validation of novel cerebrospinal fluid biomarkers for staging early Alzheimer's disease. PLoS One. 2011;6:e16032.

72. Tijms BM, Gobom J, Reus L, Jansen I, Hong S, Dobricic V, et al. Pathophysiological subtypes of Alzheimer's disease based on cerebrospinal fluid proteomics. Brain. 2020;143:3776-92.

73. Johnson ECB, Dammer EB, Duong DM, Ping L, Zhou M, Yin L, et al. Largescale proteomic analysis of Alzheimer's disease brain and cerebrospinal fluid reveals early changes in energy metabolism associated with microglia and astrocyte activation. Nat Med. 2020;26:769-80.
74. Higginbotham L, Ping L, Dammer EB, Duong DM, Zhou M, Gearing M, et al. Integrated proteomics reveals brain-based cerebrospinal fluid biomarkers in asymptomatic and symptomatic Alzheimer's disease. Sci Adv. 2020;6:eaaz9360.

75. Paterson RW, Bartlett JW, Blennow K, Fox NC, Alzheimer's Disease Neuroimaging Initiative, Shaw LM, et al. Cerebrospinal fluid markers including trefoil factor 3 are associated with neurodegeneration in amyloid-positive individuals. Transl Psychiatry. 2014;4:e419.

76. Heywood WE, Galimberti D, Bliss E, Sirka E, Paterson RW, Magdalinou NK, et al. Identification of novel CSF biomarkers for neurodegeneration and their validation by a high-throughput multiplexed targeted proteomic assay. Mol Neurodegener. 2015;10:64.

77. Brinkmalm G, Sjödin S, Simonsen AH, Hasselbalch SG, Zetterberg H, Brinkmalm A, et al. A parallel reaction monitoring mass spectrometric method for analysis of potential CSF biomarkers for Alzheimer's disease. Proteomics Clin Appl. 2018;12:1700131.

78. Duits FH, Brinkmalm G, Teunissen CE, Brinkmalm A, Scheltens P, Van Der Flier WM, et al. Synaptic proteins in CSF as potential novel biomarkers for prognosis in prodromal Alzheimer's disease. Alzheimers Res Ther. 2018;10:1-9.

79. Nagahara AH, Merrill DA, Coppola G, Tsukada S, Schroeder BE, Shaked GM, et al. Neuroprotective effects of brain-derived neurotrophic factor in rodent and primate models of Alzheimer's disease. Nat Med. 2009;15:331-7.

80. El Gaamouch F, Audrain M, Lin WJ, Beckmann N, Jiang C, Hariharan S, et al. VGF-derived peptide TLQP-21 modulates microglial function through C3aR1 signaling pathways and reduces neuropathology in 5xFAD mice. Mol Neurodegener. 2020;15:4.

81. Allen M, Carrasquillo MM, Funk C, Heavner BD, Zou F, Younkin CS, et al. Human whole genome genotype and transcriptome data for Alzheimer's and other neurodegenerative diseases. Sci Data. 2016;3:1-10.

82. Hokama M, Oka S, Leon J, Ninomiya T, Honda H, Sasaki K, et al. Altered expression of diabetes-related genes in Alzheimer's disease brains: The Hisayama study. Cereb Cortex. 2014;24:2476-88.

83. Roussarie JP, Yao V, Rodriguez-Rodriguez P, Oughtred R, Rust J, Plautz Z, et al. Selective neuronal vulnerability in Alzheimer's disease: a networkbased analysis. Neuron. 2020;107:821-35.

84. Heywood WE, Hallqvist J, Heslegrave AJ, Zetterberg H, Fenoglio $C$, Scarpini $E$, et al. CSF pro-orexin and amyloid- $\beta 38$ expression in Alzheimer's disease and frontotemporal dementia. Neurobiol Aging. 2018;72:171-6

85. van der Ende EL, Meeter LH, Stingl C, van Rooij JGJ, Stoop MP, Nijholt DAT et al. Novel CSF biomarkers in genetic frontotemporal dementia identified by proteomics. Ann Clin Transl Neurol. 2019:6:698-707.

86. Khoonsari PE, Shevchenko G, Herman S, Remnestal J, Giedraitis V, Brundin $\mathrm{R}$, et al. Improved differential diagnosis of Alzheimer's disease by integrating ELISA and mass spectrometry-based cerebrospinal fluid biomarkers. J Alzheimers Dis. 2019;67:639-51.

87. Scheltens P, De Strooper B, Kivipelto M, Holstege H, Chételat G, Teunissen CE, et al. Alzheimer's disease. Lancet. 2021;397(10284):1577-90.

88. Camporesi E, Nilsson J, Brinkmalm A, Becker B, Ashton NJ, Blennow K, et al. Fluid biomarkers for synaptic dysfunction and loss. Biomark Insights. 2020;15:1177271920950319.

89. Poljak A, Hill M, Hall RJ, MacLullich AM, Raftery MJ, Tai J, et al. Quantitative proteomics of delirium cerebrospinal fluid. Transl Psychiatry. 2014;4:e477.

90. Landén M, Grenfeldt B, Davidsson P, Stridsberg M, Regland B, Gottfries CG, et al. Reduction of chromogranin $A$ and $B$ but not $C$ in the cerebrospinal fluid in subjects with schizophrenia. Eur Neuropsychopharmacol. 1999:9:311-5. 